\title{
Superquadratic fluidic restrictors and their applications
}

\author{
V. Tesař \\ Institute of Thermomechanics ASCR v.v.i., Prague, Czech Republic
}

\begin{abstract}
In a little-known type of flow restrictors the resistance to flow is due to centrifugal force acting on the fluid rotating in a shallow cylindrical chamber into which it enters tangentially. The advantage over other restrictor types is high achievable pressure drop in relation to quite large flowpath cross-sections. The super-quadraticity - which is steeper than the quadratic rise of the pressure drop with increasing flow rate - is an interesting and yet almost unknown property of these restrictors. This paper presents examples of the effect and its applications. Keywords: flow restrictors, vortex devices, rotating flow, fluidics.
\end{abstract}

\section{Introduction}

In view of the general requirements of efficiency it may seem contradictory to common sense to develop and use hydraulic and pneumatic devices having no other purpose than to dissipate the energy of fluid that passes through them. Yet such devices, hydraulic or pneumatic restrictors (general term: fluidic restrictors) are not only useful but actually very important. Their typical application is limiting the discharge of fluid accumulated in a pressure vessel after its sudden opening. Another use is suppression of fluid flow pulsation. Related case is damping mechanical motion converted by a piston transducer into the fluid flow. Yet another use is "gagging" of the inlets into several parallel flowpaths to secure uniform flow distribution into them. There are also numerous applications in sensors: a well-known example is the evaluation of flow rate by measuring the pressure drop across a restrictor.

Presented in Fig. 1 are three different operating principles used for these tasks, named according to the ideal value of the exponent $n$ of their characteristic - the dependence of pressure drop $\Delta P$ on volume flow rate

$$
\Delta P \sim \dot{V}^{n}
$$




\begin{tabular}{|l|c|c|}
\hline LINEAR & QUADRATIC & CUBIC \\
\hline Device: Capillary & Orifice & Vortex restrictor \\
\hline Surface friction & Formation and dissipation of a jet & Centrifugal force \\
\hline
\end{tabular}

Figure 1: Three basic types of flow restrictors. It is not easy to get characteristics perfectly linear or perfectly quadratic in the wellknown capillary or orifice devices, respectively, and equally difficult to achieve is the perfectly cubic behaviour in the less known vortex restrictors.

It is advisable to replace eq. (1) by the dependence between conserved quantities: specific energy drop and mass flow rate

$$
\Delta e \sim \dot{M}^{n}
$$

Eq. (1) remains nevertheless a convenient choice (because it uses directly measurable quantities) if it is acceptable to neglect compressibility and also the difference in the kinetic energy in the inlet and outlet.

The linear characteristic (ideal exponent $n=1$ ) of the laminar capillary-type restrictors (Fig. 1) is sometimes considered desirable, mainly because the conditions in - and dynamics of - circuits composed of linearly behaving devices are amenable to analytical solutions. Usually, however, the linearity is imperfect, marred by inevitable additional non-linear components of resistance, such as the one caused by the flow development in the capillary entrance or by the formation of a jet in the exit (and the jet energy dissipated further downstream). The condition of laminarity requires small inner diameter $d$ of the capillary, prone to clogging by dirt or by objects carried with the fluid. An also unpleasant property is the ease with which the characteristic varies due to accretion, precipitation, or temperature dependence of viscosity $v$. The dissipation is characterised by Euler number

$$
\mathrm{Eu}=\frac{\pi^{2} d^{4} \Delta e}{8 \dot{V}^{2}}
$$

For a capillary of length $l$, Euler number for fully developed flow is

$$
\mathrm{Eu}=\frac{64}{\operatorname{Re}} \frac{l}{d}
$$

It is usually desirable to have $\mathrm{Re}$ as high as is compatible with the laminarity requirement (let us say $\operatorname{Re} \sim 1000$, higher values may lead to sensitivity to disturbances). Manufacturing very long capillaries, longer than about $l / d \sim 20$, may be difficult. As a result, typical Euler numbers are $\mathrm{Eu} \sim 1.3$. 
Less sensitive to the obliteration, temperature changes, and blockage by foreign objects are the orifice type restrictors, called quadratic in Fig. 1 although their actual value of the exponent $n$ in eq. (2) is usually less than the ideal $n=2$ due to the inescapable presence of wall friction, negligible only at very high Re, usually above $\mathrm{Re} \approx 10000$ (cf. Tesař [1]). Total dissipation of the energy drop $\Delta \mathrm{e}$ converted into the kinetic energy of the jet issuing from the orifice would result in $\mathrm{Eu}=1$. In real flows, typical values (depending on the orifice shape) of Euler number are around $\mathrm{Eu} \approx 1.4$ - i.e. of the same magnitude as for the linear restrictors.
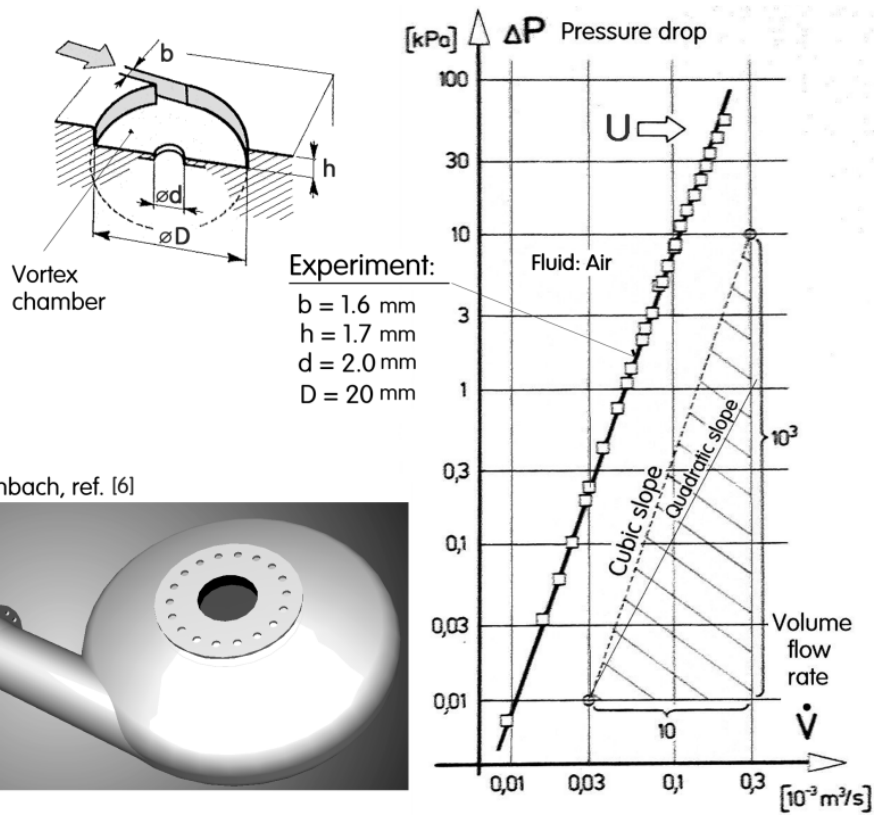

Figure 2: (Top left) Simple vortex-type flow restrictor with single inlet. Fluid enters tangentially the vortex chamber where it rotates at increasing rate as it progresses towards the central exit, opposed by centrifugal effects. (Right) Typical steady-state characteristic of vortex-type restrictor - note the cubic slope in logarithmic co-ordinates. (Bottom left) Clever manufacturing of the largest vortex restrictors: two standard pressure vessel heads welded together. Resultant geometry is not very favourable: chamber height increasing towards the exit tends to slow down rather than promote the rotation.

\section{Vortex-type restrictors}

This less known class of restrictors was invented by Thoma in 1928 [2] as one of the earliest purely fluidic (no-moving-part) devices, and later was developed in particular by Zobel [3]. While both in linear and quadratic devices the flow 
restriction is achieved by dissipating fluid energy $e$, in the vortex restrictors is used an effect actually opposing the flow in the vortex chamber (Fig. 2(top left)). It is the centrifugal force acting against the fluid motion towards the central exit if the fluid in the chamber rotates - which is easily arranged by the tangential orientation of the entrance. It is easy to achieve Euler number values as high as $\mathrm{Eu} \sim 50-$ even values near to $\mathrm{Eu} \sim 150$ are not unheard of. Rotation speed increases as fluid progresses towards the exit as the moment of momentum conservation requires the speed to be inversely proportional to the decreasing radius. Friction effects (mainly in boundary layers formed on the chamber floor and ceiling), however, break the momentum conservation. The friction may dominate at low Reynolds numbers so that for obtaining effective flow restriction, Re should be reasonably high (details: Figs. 5(left) and 11(right)), otherwise the rotation stops (as demonstrated by visualisation in related vortex mixers, Tesař and Low [5]) and the characteristic reduces to a quadratic one. The almost two orders of magnitude higher pressure drop for a given flowpath size makes them the choice for flows having to cope with occasional presence of
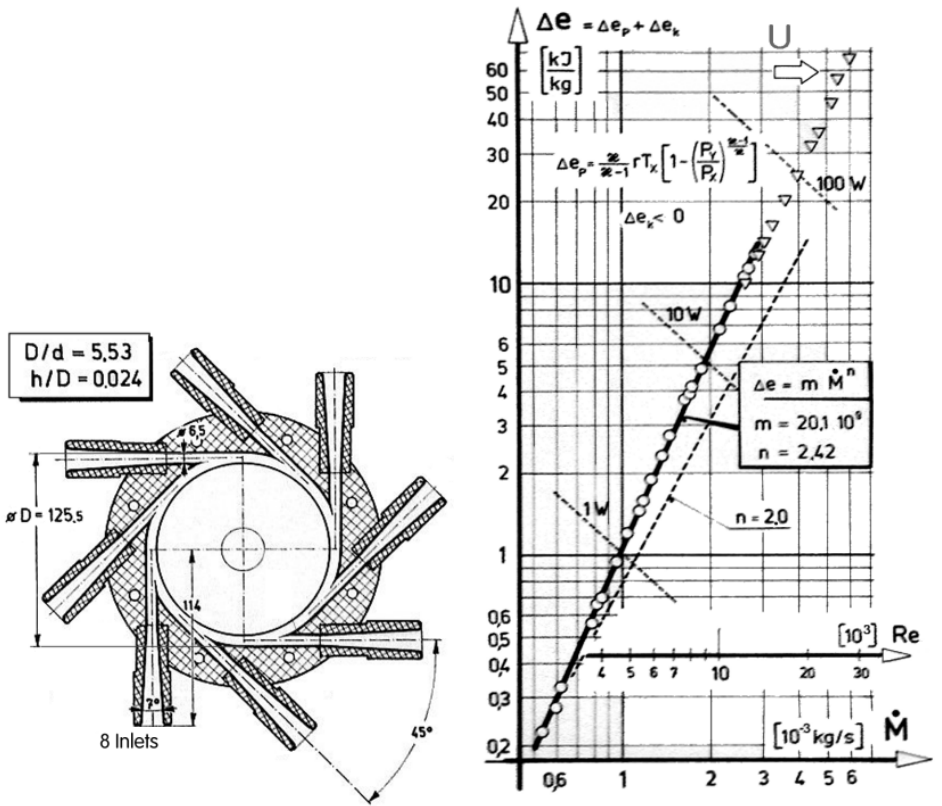

Figure 3: (Left) More tangential inlets ensure symmetry of the vortical flow and thus increase the generated fluidic resistance. Details of this design are in ref. Tesař [4]. (Right) Characteristic - dependence of specific energy on mass flow rate, here in logarithmic co-ordinates - of the design shown in the figure on the left. With its large size, it was possible to reach without compressibility effects a quite high $\mathrm{Re}$ and yet there is (as in Fig. 2(right)) the decreased-slope region $\mathrm{U}$ at high flow rates. 
foreign objects (Brombach et al. [6]). Those used in rainwater retention basins, Brombach [7] - an example is shown in Fig. 3(bottom left) - can resist high pressure drops while the physical dimension of their smallest cross sections are large enough to be not blocked even by objects as large as dead small animals, not infrequently carried with the rainwater.

Not only typical values of $\mathrm{Eu}$ in vortex type restrictors are very high - they were found to increase with increasing flow rate, which is the very opposite to the typical decrease of Eu with increasing Re in most other fluidic devices.
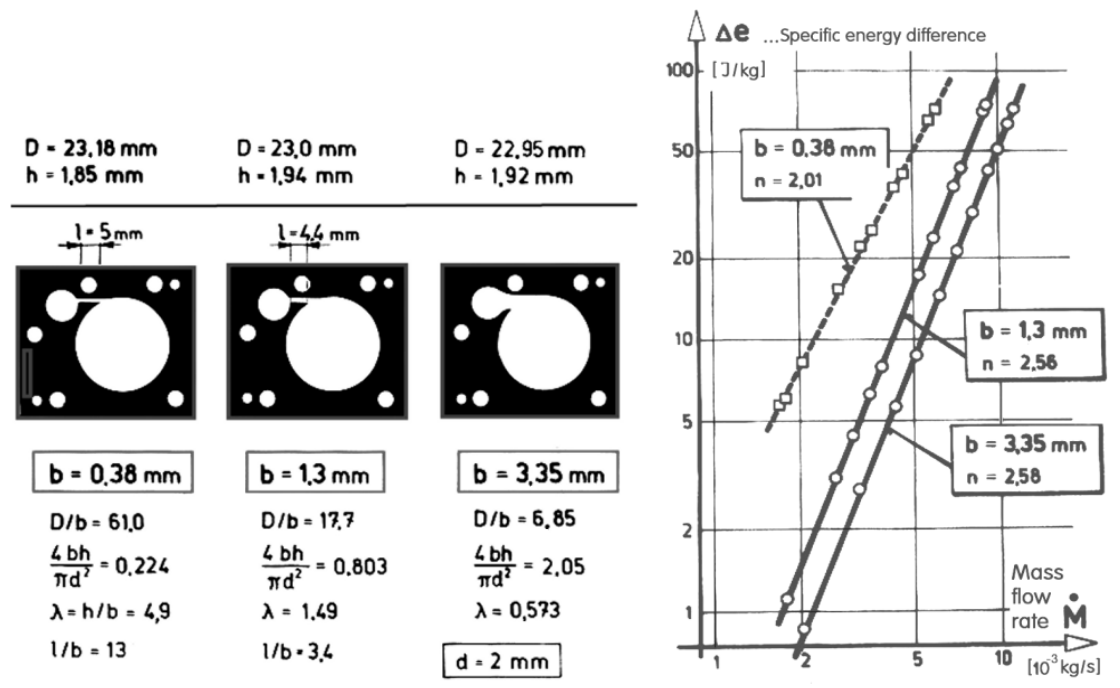

Figure 4: (Left) Experimental tests of influence of the tangential inlet width $b$. Right) Characteristics obtained with the three plates shown in the figure on the left demonstrate the negligible effect of the width $b$ on superquadraticity - unless the inlet is extremely wide, apparently leading to too slow rotation in the chamber.

\section{Superquadratic behaviour}

This increase of $\mathrm{Eu}$ with increasing $\mathrm{Re}$ is the superquadratic behaviour (Tesař [8], Brombach [9]), originally found in experiments with the small, shallow-chamber, single-inlet restrictor shown in Fig. 2(top left). The exponent $n$ (eq. (1)) had the cubic law value $n=3$ across several decimal orders of the pressure drop (Fig. 2(right)). This was and still remains rather surprising, in view of the otherwise almost ubiquitous quadratic behaviour in fluidics. Those few (extremely rare) other examples of superquadratic behaviour were known so far only in a narrow Reynolds number range, since they are usually associated with transition between two regimes - and therefore tend to be unstable.

Later, the phenomenon was again found to be present (though mostly unnoticed) in many devices of the vortex type, irrespective of the size or the number of inlets (Fig. 3). In many cases, e.g. in the domed shapes like that in 
Fig. 2(right), the exponent may be only slightly above $n \sim 2$. The data presented in Figs. 4, 5 and 10(left) were collected in (unproductive) search for an exponent $\mathrm{n}$ higher than the cubic law value $n=3$. The experiments involved systematic variations of the three geometric parameters $b / D, h / D$, and $d / D$ in a design according to Fig. 2(top left). While $b / D$ is seen in Fig. 4 to have a negligible influence - as has also the number of inlets, Fig. 3 (as long as this does not make the entrance velocity too slow, as is the case $b=0.38 \mathrm{~mm}$ in Fig. 4(left)) - the variations of $h / D$, and $d / D$ did lead to changes in the exponent $n$ (Figs. 5(right), 10 (left)), but with the conclusion that the value $n=3$ is actually the achievable maximum that was chosen fortuitously in the initial experiment.
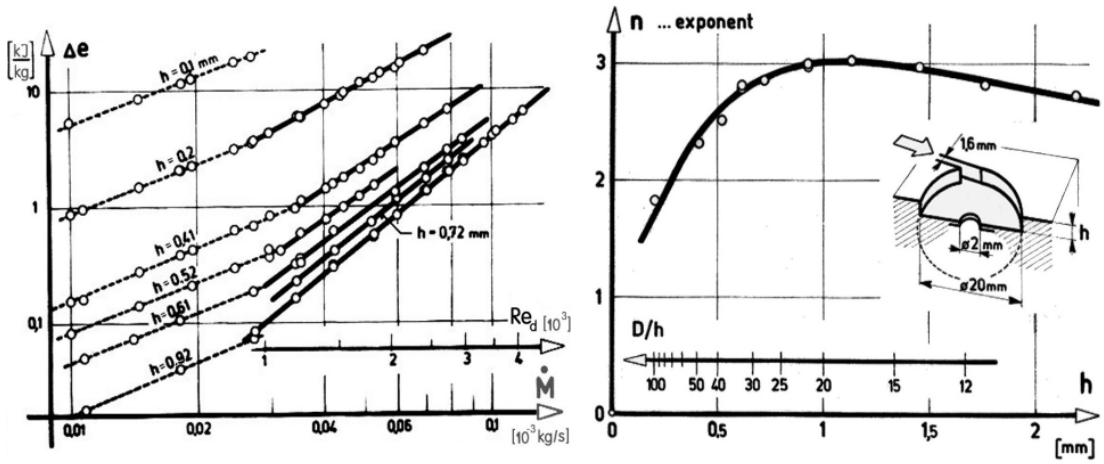

Figure 5: (Left) Characteristics obtained in testing the influence of the chamber height $h$. Loss of superquadraticity is found at very low Re where friction stops the rotation. (Right) Cubic behaviour $(n=3)$ was the limit found near $h \sim 20 \mathrm{D}$.

\section{Significance for possible applications}

Potential uses of the rapid build-up of pressure with increasing flow rate in superquadratic devices are numerous and often quite interesting, though not widely known. The more rapid rise of the pressure across the vortex chamber with increasing flow rate shown in Fig. 6 makes possible more precise flow rate measurement (or relaxed demands on the manometer), Tesař [11]. Another particularly sensitive flow rate measurement method with the vortex restrictor was described by Tesař in [12]. Another use is the gagging of the entrances into parallel evaporator tubes, Tesar [13], to counter the instability associated with the segment of negative slope (Fig. 7(left)). The advantage gained by the cubic characteristic is reduction of the overall pressure (and therefore the input power) required for driving the fluid through the system. In [14] Tesar describes the advantages offered by superquadratic flow restrictors in shock absorbers.

Useful applications were also found for the series connection of the vortex restrictor $V$ with standard orifice-type quadratic restrictor $R$, as shown in Figs. 7(right) and 8(left). The experimental results presented in Fig. 8(right) demonstrate that the ratio of their pressure drops varies in the perfectly linear manner with the flow rate passing through both devices. Obviously, the 

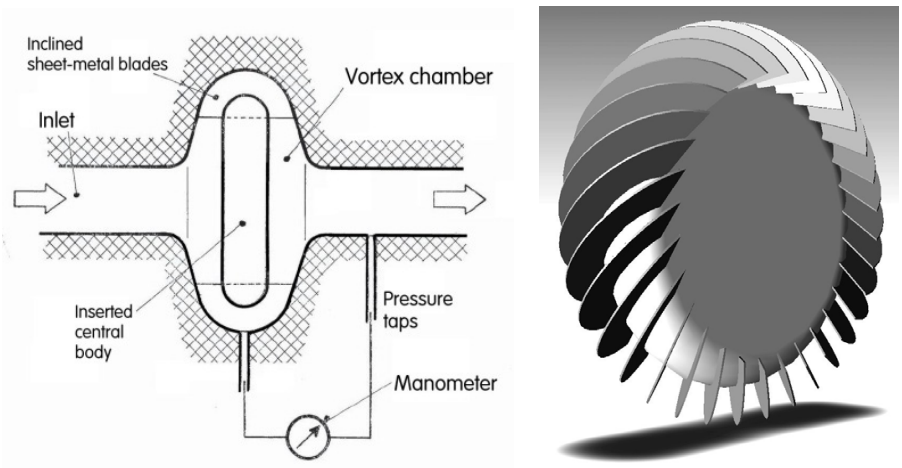

Figure 6: (Left) Flowmeter with vortical flow generated by inclined vanes inserted into slits of the central body circumference. Superquadraticity increases the measured pressure drop. (Right) The central body with simple plane vanes (they may be bent to evade separation on the leading edges).
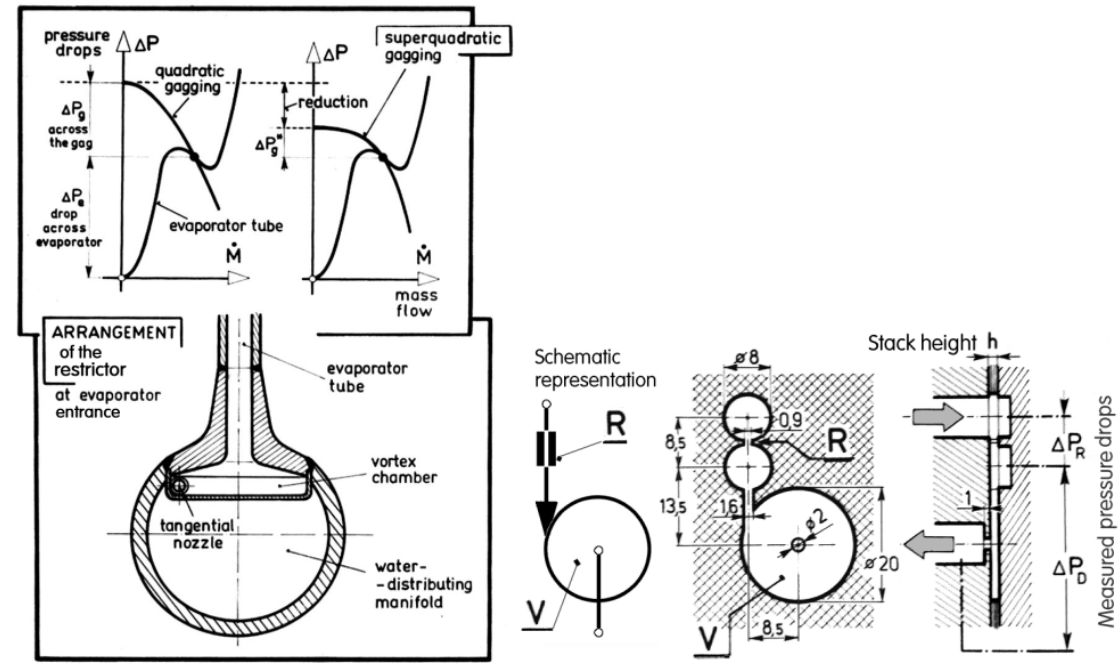

Figure 7: (Left) Inlets into the evaporator tubes. Instability due to negative slope in a part of evaporator characteristics is eliminated by gagging, superquadraticity reduces the pressure delivered by the supply pump. (Right) Series-connected quadratic restrictor $\mathrm{R}$ and the vortex restrictor $\mathrm{V}$ as they were used in the tests (dimensions in millimetres).

deviations from the ideal $n=3$ of the vortex valve $\mathrm{V}$ and from $n=2$ of the orifice $\mathrm{R}$ cancel mutually so that the slope of the ratio is constant over at least a decimal order of flow rate magnitude. Tesař [15] describes the use of this linearity in a sensor employing the property of resistance ratios in a Wheatstone bridge. 


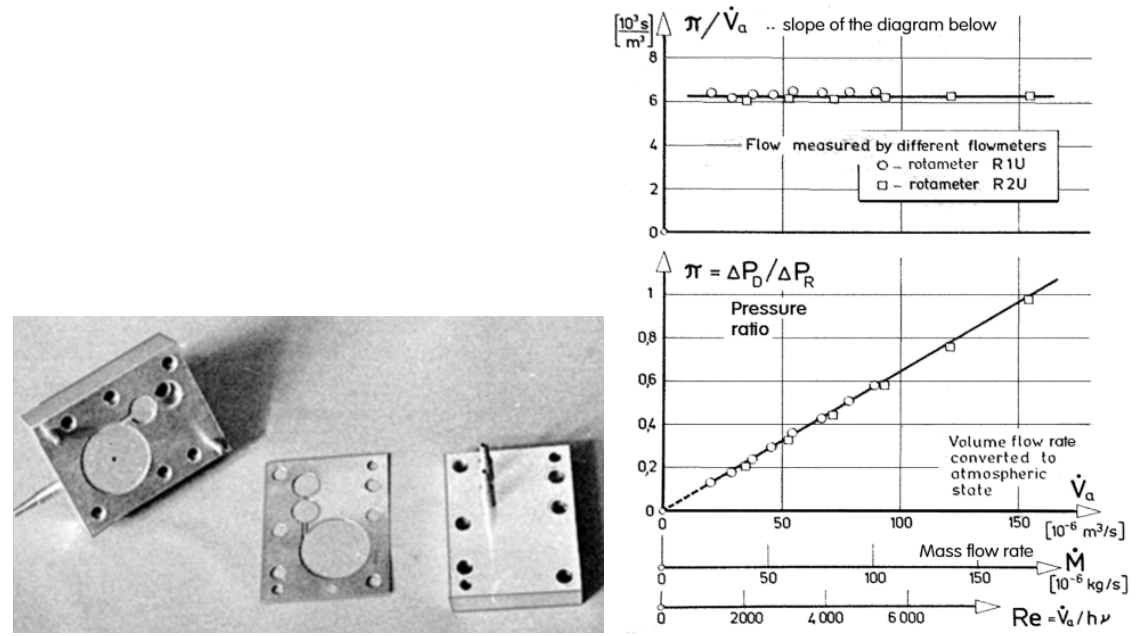

Figure 8: (Left) Photograph of laboratory model containing the two different restrictors according to Fig. 7(left). They were made in a stack of thin foils so that it was possible to change the height $h$ by varying the number of foils in the stack. (Right) Experimental results obtained with the pair of restrictors in series shown in Fig. 7(left). Ratio of the pressure drop $\Delta P_{\mathrm{D}}$ across the vortex-type restrictor $\mathrm{V}$ to $\Delta P_{\mathrm{R}}$ across the orifice-type restrictor $\mathrm{R}$ varies in strictly linear manner with the flow rate passing through the two devices as if their characteristics were purely cubic and purely quadratic, respectively. Apparently, deviations from the ideal power laws cancel themselves in evaluation of the ratio.

Perhaps even more useful is the other connection - the parallel one - of the pair of restrictors $V$ and $R$, as shown schematically in Fig. 9(right). The different properties cause a change in the ratio of the two output flows if the pressure increases. The outputs may be connected to the inputs of a fluidic jet-deflection amplifier, which then reacts by generating an amplified output signal indicating (with proper sign) the deviation from a desirable condition (zero difference set by adjusting the orifice restrictor). The layout may be actually simpler than suggested by the schematic representation since the role of the orifice resistor $\mathrm{R}$ may be fulfilled by any component already present in the system (due to the usual quadratic hydrodynamic characteristics). The advantage of this method of sensing the deviations from a desired flow rate (or pressure) is the robustness (operation, e.g., at a high temperature), low cost (just a shallow cylindrical cavity is all that is necessary) and no need for bringing electricity to the sensor.

Described in Tesař [16] is the extremely simple, no-moving-part regulator used to keep a constant total regulated flow. This bifurcates into the parallelconnected $\mathrm{R}$ and $\mathrm{V}$ restrictors, as shown in Fig. 9(right). The difference in the flow rates, Fig. 9(left), is used in the vortex amplifier valve $[17,18]$ - the third component of the regulator, besides the resistors $\mathrm{V}$ and $\mathrm{R}$. The tangential inlet 
flow into the vortex amplifier, passing through the quadratic-behaving nozzle e, increases with increasing total flow more rapidly than the radial inflow so that the total flow is turned down. Without a feedback, the control effect is only approximate, but the advantage is the extreme simplicity (with consequent low cost) and robustness. A similar pressure regulator may be built on the same principle, with just interchanged radial and tangential inlets into the vortex valve. This was described as a part of a fuel flow control device in Tesař [19].

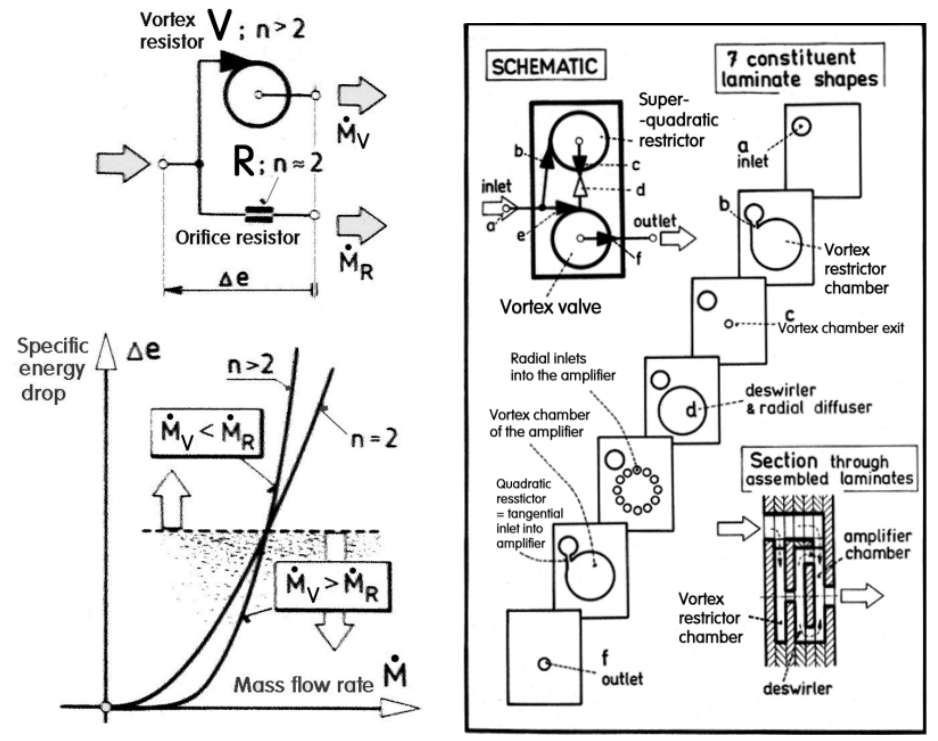

Figure 9: (Left) Schematic representation of orifice-type $R$ and the vortextype $\mathrm{V}$ restrictors in parallel and (below) their intersecting characteristics. Above the intersection more fluid passes through the quadratic restrictor. Below that point the fluid prefers flowing through the vortex device. (Right) The principle described in the figure on the left applied to control of a vortex amplifier valve keeping (in an open-loop control) a constant total flow passing through the set of 7 plates in which the circular holes form the flow regulator.

\section{Transition into the rotation-less regime $K$}

In the early stages of the search for high values of the exponent $n$ (before the experience has shown the cubic case is the extreme, Figs. 5(left) and 10(right)) it was believed that high $n$ may be obtained by extremely vigorous rotation in the vortex chamber produced by extreme ratios of vortex chamber diameter $D$ to the exit diameter $d$. The model made for these tests is shown in Fig. 10(right). The disillusion learned is apparent in the results presented in Fig. 11: the large shallow chamber only resulted in dominance of friction, which limits the 
superquadratic behaviour to the range of Reynolds number above the transition at (T. Tests with increasing $d / D$ did not result in the high exponent but just in a removal of progressively higher Reynolds numbers from the useful operating region.
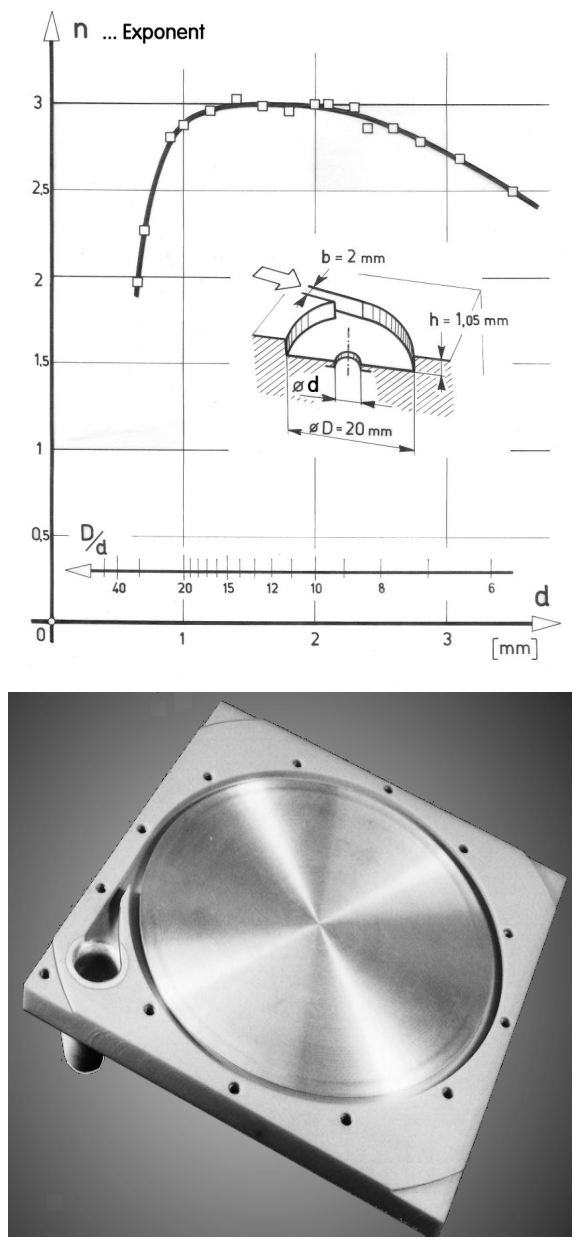

Figure 10: (Left) Dependence of the exponent $n$ on the exit diameter $d$ of the basic restrictor as shown in Fig. 2(top left). (Right) Restrictor model design made for experiments with large ratio of vortex chamber diameter $D$ to exit diameter $d$. The exit is not visible in this photograph as it is in the top (removed) part of the body. The groove on the periphery of the vortex chamber was intended to improve the flow symmetry. 


\section{Upper limit: regime $\mathrm{U}$}

Closer investigations of vortex restrictor characteristics have revealed that the cubic or near-cubic region, despite the wide range of Reynolds numbers in which it was found, is not only limited by the transition at (T) at small flow rates but has also a limit at high flow rates. An onset of deviation $U$ from the behaviour was already found at the upper end of the range of experimental conditions in the earliest tests as shown in Fig. 2(right). This effect is not very prominent - in fact, the behaviour remains superquadratic. The deviation was initially thought to be a mere experimental imperfection, but plotting in terms of Eu (Fig. 12(left)) has shown it to be a systematic phenomenon. Because it was found always at very high pressure drops $\Delta P$, necessary to force the large flow through the small models (e.g., Fig. 2(right)), an explanation was later sought in compressibility. Only after the effect was investigated in detail by numerical flowfield computations

(Fig. 12(right)) and by evaluation of circulation $\Gamma$ (by a method analogous to the one used in Tesar and Low [5]) this upper-limit transition was explained to be the consequence of the vortex breakdown.
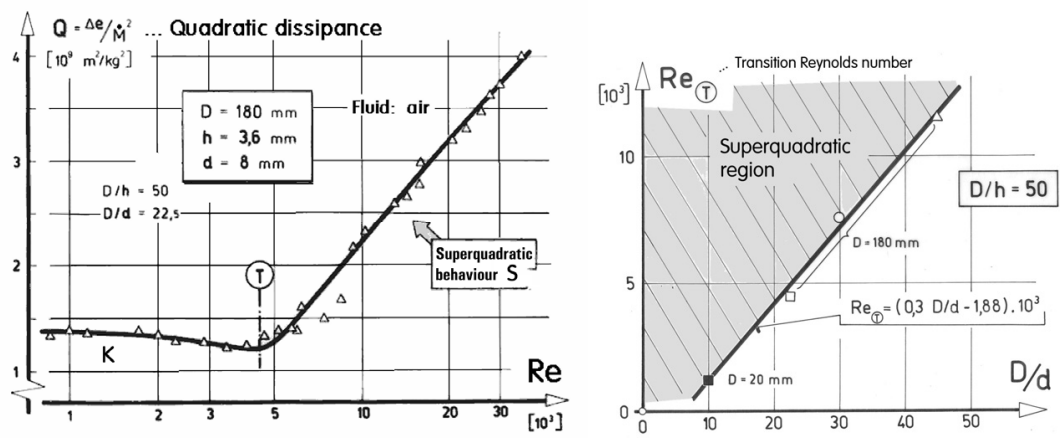

Figure 11: (Left) An example of results obtained with the model shown in Fig. 10(right). The superquadratic behaviour was found only above the transition at $(\mathrm{T}$-below which there is the more or less quadratic regime K. (Right) Instead of resulting in extremely high values of the exponent $n$ as originally expected, the very small diameters $d$ of the exit resulted in large Reynolds number of the transition. 

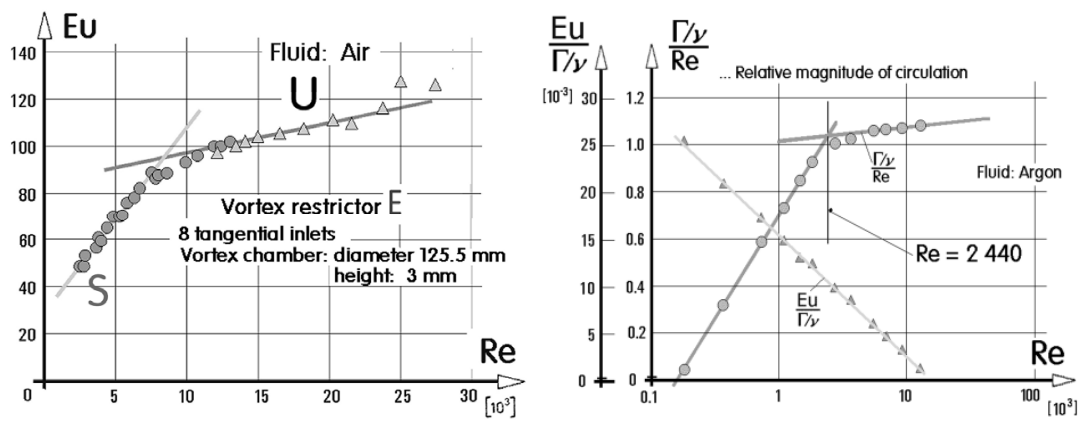

Figure 12: (Left) Dependence of Euler number Eu on Re evaluated for the design from Fig. 3(left) shows clearly the transition into the $U$ flow regime characterized by less steep $\mathrm{Eu}$ growth with increasing Re. (Right) Circulation $\Gamma$ in the vortex chamber exit (argon was used to simulate uranium hexafluoride, less pleasant to work with) shows transition into the $\mathrm{U}$ flow regime. The change ceases to become discernible when the circulation is non-dimensionalised with respect to Euler number.
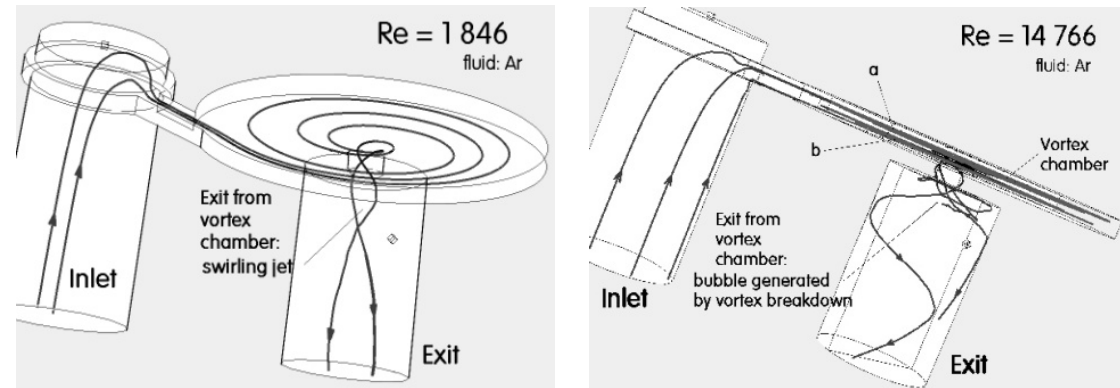

Figure 13: (Left) Computed pathlines for the basic superquadratic flow regime: fluid leaves the vortex chamber exit as a narrow swirling jet.(Right) Pathlines for very high Re flow regime U. There is a vortex breakdown bubble immediately downstream from the exit. Also interesting is the separation of the arbitrarily chosen pathlines into the upper $a$ and lower $b$ flow through the chamber, indicative of the fluid passing through the boundary layers.

\section{Conclusions}

Vortex type restrictors and their interesting properties are not as much known and used as they deserve. The paper focuses one of their properties: the superquadratic behaviour, which offers a number of particularly useful application possibilities. 


\section{Acknowledgements}

Gratefully acknowledged is the support by the research plan AV0Z20760514, by grants TA02020795 from TAČR as well as P101/11/J019 donated by GAČR.

\section{References}

[1] Tesař V., Characterisation of subsonic axisymmetric nozzles, Chemical Engineering Research and Design, Vol. 86, Issue 11, p. 1253, 2008.

[2] Thoma D., Fluid lines, U. S. Patent No. 1,839,616, 1928.

[3] Zobel R., Experiments on a hydraulic reversing elbow, UKAEA Risley Transl. into English, No. 439, Mitteilungen des Hydr. Inst., Munich, Germany, Vol. (Bd.) 8, p. 1, 1936.

[4] Tesař V.: Fluidics: the answer to problems of handling hazardous fluids, Proc. of $4^{\text {th }}$ Int. Conf. SAFE IV, p. 465, Antwerp. 2011.

[5] Tesař V., Low Y.Y., Study of shallow-chamber vortex mixers for microchemical applications, Proc. of 9th Internat. Symp. on Flow Visualization, Edinburgh, paper No. 445, 2000.

[6] Brombach H. et al. Energieabbau mit Wirbeldrosseln in einer Waschwasser-rohrleitung eines Kalksteibruches, 3R International, Heft 5, p. 330, 1989.

[7] Brombach H., Flood protection by vortex valves, Journal of Dynamic Systems, Measurement, and Control, ASME, Vol. 3, p. 338, 1981.

[8] Tesař V., Superquadratic behaviour of vortex diodes, Proc. of IFAC Symp. 'Pneumatic and Hydraulic Components.' Warsaw, Poland, p. 79, 1980.

[9] Brombach H., Diskusionsbeitrag zum Aufsatz G. Koplitz-Weissgerber: Berechnungsverfahren für kreisformige Wirbeldrosseln, in German, Wasserwirtschaft Bd. 71, Nr. 7+8, p. 218, 1981.

[10] Kotowski A., Wójtowicz P., Analysis of hydraulic parameters of cylindrical vortex regulators, Environment Protection Engng., Vol. 34, p. 43, 2008

[11] Tesař V., Apparatus for measurement of fluid flow, Czechoslovak Patent No. 195802, filed 31 ${ }^{\text {st }}$ Aug. 1977.

[12] Tesař V., Connection of a jet-type flow sensor, Czechoslovak Patent No. 195116, filed $20^{\text {th }}$ Sept. 1977.

[13] Tesař V., Gagging of the inlet of liquid into evaporator tubes of a steam generator, Czechoslovak Patent No. 192856, $1^{\text {st }}$ Sept. 1977.

[14] Tesař V., Setup for damping fluid flow and of mechanical motion converted into fluid flow, Czechoslovak Patent No. 212574, filed 30 ${ }^{\text {th }}$ Nov. 1979.

[15] Tesař V., Ways of evaluating fluid flow and means for performing it, Czechoslovak Patent No. 202 201, filed $1^{\text {st }}$ Sept. 1977.

[16] Tesař V., Fluid flow regulator, Czechoslovak Patent No. 186043, filed $20^{\text {th }}$ Oct. 1976.

[17] Wormley D.N., An analytical model for incompressible flow in short vortex chambers, Trans. of ASME, Journ. of Basic Engineering, p. 264, 1969.

[18] Tesař V., Pressure-driven microfluidics, Artech House Publ., USA, 2007.

[19] Tesař V., Ways and means for generating a small controllable liquid flow, Czechoslovak Patent No. 186614, filed 28 ${ }^{\text {th }}$ Dec. 1976. 